reported to authorities and infections with STIs/HIV. These were collated and analysed using EPI INFO two thousand and two.

Out of four hundred respondents, sexual violence cases were reported from three hundred and eighty nine, ninety seven percent respondents out of which rape and Incest accounted for thirty three percent and fourteen percent respectively. Out of these forty seven percent respondents, thirty two of them reported being infected with HIV and other STIs. HIV/STIs among those who had incest and were raped were significantly associated with sexual violence. Other sexual practises were significantly associated with sexual violence. Fathers and neighbours were the most prevalent perpetrators of sexual violence in girls and young women.

Conclusions The study indicated a significant trend in sexual violence over time. Sexual violence within age bracket one to ten is on the increase while ages greater than twenty eight are on the decline. The study also suggests that sexual violence is one of the factors that increase the acquisition of HIV/STIs in girls and young women. Regular surveys would help in developing new strategies for control and prevention of sexual violence in girls and young women in Lagos Nigeria

\section{P3.389 SUCCESFULLY INVOLVING TEENAGERS FOR EFFECTIVE SEXUAL HEALTH CAMPAIGNS THROUGH SOCIAL MEDIA}

doi:10.1136/sextrans-2013-051184.0842

\section{E Fisser. Soa Aids Nederland, Amsterdam, The Netherlands}

Dutch youth have extensive knowledge on and a very positive attitude towards safe sex. Over $75 \%$ has the intention to maintain condom use with a new partner until both have been tested for an sti. Our next goal was to influence behaviour directly. We provided emotional arguments; a good lover discusses wishes and boundaries with his or her partner. Condom use should be a part of that conversation.

The best moment to bring up condom use is right before you take of your pants. We communicated a cue; at this moment you should act this way to adher to the social norm. We needed to be as lively as possible so teenagers could project themselves into these scenarios. We used a social media strategy to co-create them.

We co-operated with several niche youth-run online communities. We offered no rewards or prizes to participants other than be taken seriously and have their input being used in a television campaign. We were open, honoust, active and accessible. We reached over 3 million readers, our webvideos were watched over 2 million times. We received over 21.000 handwritten responses and over 60.000 votes on our polls. Interactivity with and between teenagers rose weekly during the campaign.

This co-creation led to three tv commercials showing six scenarios and three radio commercials. $91 \%$ of our target audience was reached.

The resulting campaign was well received (7.3 appreciation, benchmark: 6.8) and very effective: correct message transfer was $98 \%$. We also found a significant behavioural result: The number of youths who reported bringing up the subject of condoms before taking of their pants rose from $56 \%$ to $74 \%$.

\section{P3.390 FACTORS PREDICTING ATTITUDE OF FIRST YEAR UNIVERSITY STUDENTS TOWARDS STI AND HIV IN OGUN STATE, NIGERIA}

doi:10.1136/sextrans-2013-051184.0843

o A Adekeye. Covenant University, Ota, Nigeria

Background Sexually transmitted infections (STIs) and Human immunodeficiency virus and acquired immune-deficiency syndrome (HIV/AIDS) are global problems and currently over 100 mil- lion STIs occur each year in people within the 15-24 age bracket. Young people between ages 15 and 24 also account for more than fifty (50) percent of all HIV infections throughout the world.

Methods A survey research questionnaire made up of three trajectories including sexual behaviour scale, attitude towards STI/HIV/ AIDS scale and knowledge of STI/HIV/AIDS scale was used in this study ( $n=226$, mean $=18$.3years). The study made use of frequency counts, percentage and regression analysis. The SPSS software was used to analyse the data.

Results The study indicates a fairly high knowledge level of STI/ HIV (89.4\%) with more males (87\%) and younger participants (88\%) possessing good knowledge of STI/HIV. Majority of the participants are sexually active $(63.3 \%)$ and of this are more males $(61.3 \%)$ and younger participants $(60 \%)$. Findings show that age $(\beta=0.025 ; t=0.04 ; p>0.05)$ of the three predictor variables was not a predictor of attitude towards STI/HIV. However, knowledge of STI/HIV $(\beta=0.459 ; \mathrm{t}=5.032 ; \mathrm{p}<0.05)$ and sexual behaviour $(\beta=0.341 ; t=4.278 ; p<0.05)$ were strong predictors of attitude towards STI/HIV.

Conclusion This study shows the need for strong advocacy, enlightenment and community mobilisation for improved awareness of STI/HIV. Local, community and religious leaders, including youth leaders should be incorporated into the drive to increase awareness and knowledge of STI/HIV/AIDS among young people in Nigeria.

\section{P3.391 CONCURRENT PARTNERS. A PREDICTOR OF CHLAMYDIA}

doi:10.1136/sextrans-2013-051184.0844

${ }^{1,2} \mathbf{M}$ J Joergensen, ${ }^{2} \mathrm{~F}$ Olesen, ${ }^{3} \mathrm{H}$ M Terkildsen, ${ }^{2} \mathrm{~K} S$ Christensen, 'B Andersen. 'Department of Public Health Programs, Randers Regional Hospital, Randers NØ, Denmark; 'Research Unit for General Practice, Aarhus University, Aarhus, Denmark; ${ }^{3}$ Section for Health promotion and Health Services, Department of Public Health, Aarhus University, Aarhus, Denmark

Background Chlamydia trachomatis (C. trachomatis) is the most common sexually transmitted bacterial infection among young individuals, and Chlamydia transmission is closely related to sexual behaviour. Previous studies have found overlap between sexual partnerships to be a possible predictor of $C$. trachomatis, but the importance of this finding has only been briefly described when other significant predictors are also taken into account.

Aim The aim of the study was to examine the importance of overlap between sexual partnerships as a predictor of C. trachomatis infection in young Danes aged 15-29 years.

Method Detailed sexual behaviour data were collected via a webbased questionnaire. A total of 1,445 young Danes with a laboratory-verified C. trachomatis infection registered in the Central Denmark Region and 1,000 randomly selected Danes (control group) aged 15-29 years were invited to participate. Using multivariate analysis, we calculated the odds ratio (OR) for having overlap between sexual partnerships in the group of $C$. trachomatis infected individuals as compared with the controls.

Results The participation rates were 15.5\% (217/1,445) among the C. trachomatis infected and $35.6 \%(348 / 1,000)$ in the general population. In the multivariate analysis, we found that young Danes diagnosed with a C. trachomatis infection were more likely to have had concurrent partnerships than individuals in the control group.

- At least 1 overlap between sexual partners; Adj. OR = 10.1 (95\% CI: 4.8-21.1)

- At least 2 overlaps between sexual partners; Adj. OR $=0.6$ (95\% CI: 2.2-51.1)

- At least 3 overlaps between sexual partners; Adj. OR = 9.9 (95\% CI: 2.0-48.4)

Conclusion Concurrent sexual partnerships are an important predictor for C. trachomatis infection in young adults aged 15-29 years when other significant predictors are taken into account. 